
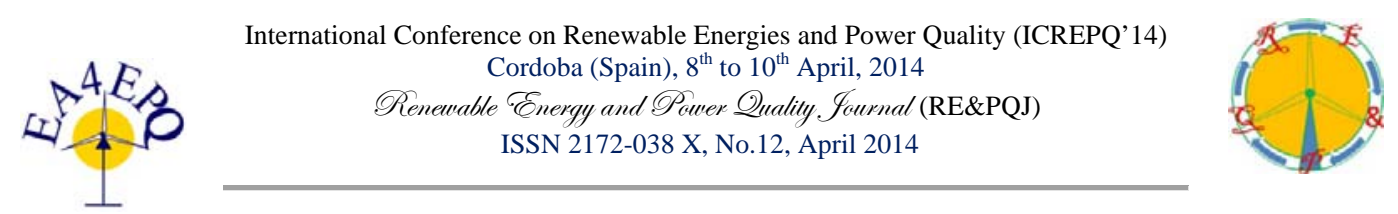

\title{
Object-Oriented Modelling of Small Hydropower Plants
}

\author{
M. L. Ruz, J. Garrido, S. Fragoso and F. Vázquez \\ Department of Computer Science and Numerical Analysis \\ E.P.S., Córdoba University \\ Campus of Rabanales - 14071 Córdoba (Spain) \\ Phone/Fax number: +34 957 218729, e-mail: mario.ruz@uco.es, fvazquez@uco.es
}

\begin{abstract}
The improvement of the exploitation of energy resources in power stations is a topic of growing interest. However, experimentation costs in order to increase productivity are very high, either because the possible equipment to change would be very expensive, or simply, because the plant would have to stop. In such cases, the simulation is a fast and cheap way to analyze the power plant behavior in order to try to improve its performance by means of modifying the control strategy or changing some elements of the plant. This work is focused on small hydropower plants and it presents the design of a library for modelling these power stations. After reviewing the desirable features of simulation, an approach based on an object oriented modelling language is used. This approach allows the different elements of the plant (dam, gates, turbines, tubes, generators...) to be created and validated individually, and facilitates their interconnections in order to set up easily and quickly models of different stations. By simulating these models, it is possible to obtain interesting information, like reservoir level, flows, pressures, head losses in any component, turbine efficiencies and so on. The modelling of two real hydropower plants installed in Córdoba is presented.
\end{abstract}

\section{Key words}

Object-oriented modelling, hydropower plant, simulation, component library.

\section{Introduction}

There are important reasons for modelling and simulation: testing and optimizing a system design previous to its construction, avoiding design errors, improving quality, reducing costs, assessing performance, predicting behavior, training operators, and so on. Simulation is a very useful tool in those particular cases in which the cost of experimentation are very high, either by the high cost of the equipment or because the system cannot be stopped, as usually occurs in power plants. Currently, the improvement in the utilization of energy resources in these plants is a topic of great interest. An example is hydropower plants, especially small hydropower stations, which do not have a large environmental impact and additionally are widespread in all watersheds. Many of these plants were created more than five decades ago and its operation could be improved. The simulation of a complete model of the plant would be a quick and inexpensive way to analyze and improve its performance by changing part of the control strategy or modifying some of its elements.

The object-oriented modelling (OOM) is one of the latest modelling paradigms that spread in the nineties, and it has already been applied to the modelling of power plants and their applications [1]. A hydropower station can be seen as a combination of components such as generators, turbines, valves, control systems, and so on. Using OOM, all components are treated as objects through which the modeler can increase the complexity (encapsulation), reuse models (inheritance and aggregation), and create separate models easy to maintain. In addition, the modular programming feature allows the modeler to create the whole plant model by combining simple components that model different parts of the plant [2].

In this paper, the object-oriented modelling application to small hydropower plants is shown. The modelling of different elements of such plants is carried out with EcosimPro in such a way that they can be used to build a complete model of different stations. This is illustrated in two examples: the Villafranca power plant with run-ofriver scheme and the San Rafael de Navallana pumpedstorage station (both in Spain). Simulating the overall plant model is intended to obtain information such as the level of the reservoir, flow rates, pressures and losses in different elements, the performance of the turbine, the power generated, and so on. This information can be useful for optimization of the plant.

\section{Small hydropower plants}

A small hydropower plant is the set of facilities and other infrastructure built with the aim of turning the potential energy of a water stream into useful electrical energy. This electrical energy is self-consumed in the same generation place or sold to the commercial power grid in order to obtain economic benefits. These electricity production facilities are usually placed within the river 
ecosystem. A hydropower plant is considered a small plant when the installed capacity is less or equal than 10000 $\mathrm{kVA}$. The term of micro-hydropower plant is used when the installed capacity does not exceed $1000 \mathrm{kVA}$.

In this paper the modelling and simulation of two different types of small hydropower stations are shown: a pumpedstorage station and a plant with run of river scheme. In the run-of-river scheme the turbine only generates power when the water is available and provided by the river. When the river flow falls below some predetermined threshold value, generation ceases. Low head schemes are typically built in river valleys. Two technological options can be selected. Either the water is diverted to a power intake with a short penstock, or the head is created by a small weir which is provided with sector gates and an integrated intake, powerhouse and fish ladder (Fig. 1). Because of the fact that the gross head in these stations (run of river scheme) is small, Francis or Kaplan turbines are commonly chosen [3]. In normal operation, this type of plant tries that the river water flow passes through the turbines while the upper water level is being controlled in order to maintain a minimum head. Nevertheless, when the river flow is greater than the turbine discharges and the reservoir level exceeds its highest reference, the governor system of the gates comes into the scene and controls the reservoir level.
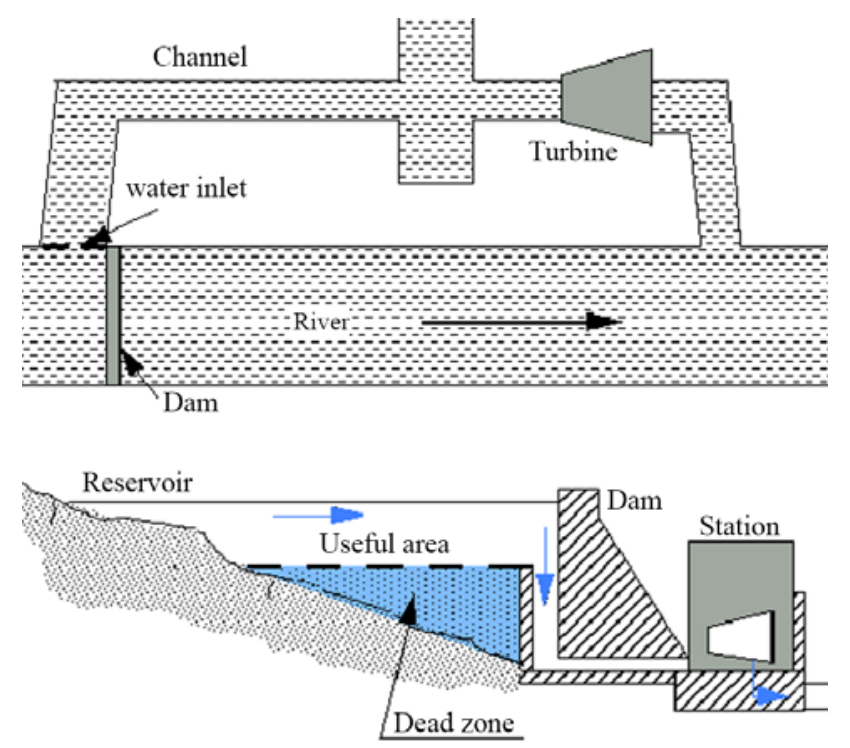

Fig. 1. Hydropower plants with run of river schemes (top) and with pumped-storage scheme (bottom).

In the pumped-storage hydropower plants, a dam is built near the river forming a reservoir which stores water from rain and snowmelt. The water is taken from the reservoir and directed towards the turbines through outlets that are usually on the dam itself, and to a certain height below the maximum reservoir level. The water intake divides the reservoir into two zones: the area between the outlet and the free surface, called useful area because only the water in this area can generate power; and the area below the outlet, called dead zone (Figure 1). This kind of station is suitable when the hydraulic head and the water flow are large. It is usually located in steep places, where it is easier to build a dam to cut the natural course of the river and the water can be stored. The power station can be placed at the foot of dam to take advantage of the dam height, or downstream of the dam so that the water head is greater. In the latter case, they are called mixed plants and water is conducted, from the dam to the place where the turbines are located, through galleries or penstocks.

\section{Modelling of the library components}

Due to the high complexity of hydroelectric plants, the use of OMM philosophy to develop a library of components is a good choice, because it offers significant advantages such as the inheritance, encapsulation, reuse and modularity features. Dymola, OMOLA or BEDS can be included among the pioneers of OMM languages. There is a tendency of unification of methods and syntax between these languages, generating a certain standard called MODELICA. This paper discusses the common features of these languages particularized to EcosimPro, which is an OOM simulation tool designed in Spain by EA International under contract with the European Space Agency.

Any of the above languages is based on the utilization of libraries, which are the basic elements used by OOM languages to organize the information. The basic purpose of a library is to store a set of interrelated elements. As an example, this paper describes the development of a library for modelling small hydropower plants, based on EcosimPro. The basic idea of implementation is to decompose the plant into components that are as simple as possible and then, to start from the bottom up, connecting basic components into more complicated classes, until the top-level model is achieved.

Before that, in the first stage, the individual basic components must be modeled and validated (that is, their domain of validity must be contrasted with the real system). For instance, Fig. 2 shows a photograph of a Francis turbine and its corresponding scheme generated for the EcosimPro graphics library. These components can be modeled from their constitutive equations or from their performance curves. The case shown in Fig. 2 is modeled in this second way, from the performance-flow curves obtained experimentally. The EcosimPro environment has a set of curve interpolation tools, whose results are obtained dynamically during simulation [4].

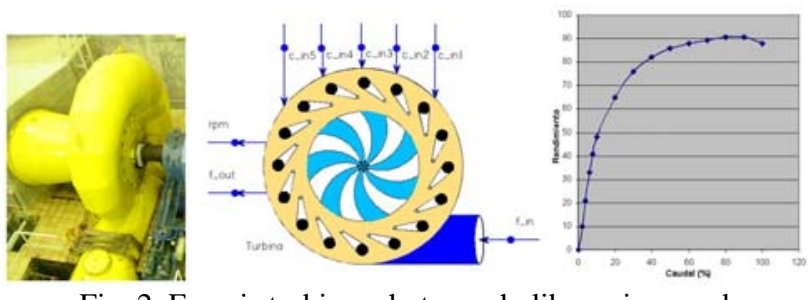

Fig. 2. Francis turbine: photograph, library icon and performance-flow curve.

Figure 3 shows the graphic symbols of some other components of the library, highlighting the connection ports (hydraulic, analog, digital), the reservoir, hydraulic structures (reservoir inlets and outlets, spillway radial gates, stoney gates, valves), turbines (Francis, Kaplan), different conduits (pipe, elbows, branches, junctions, 
expansions, contractions, bypass), control systems (PLC, PID, gate automation system), electromechanical equipment (synchronous generator, signal meter, etc.). All these models are built on the basis of physical principles of conservation of mass, energy and momentum.

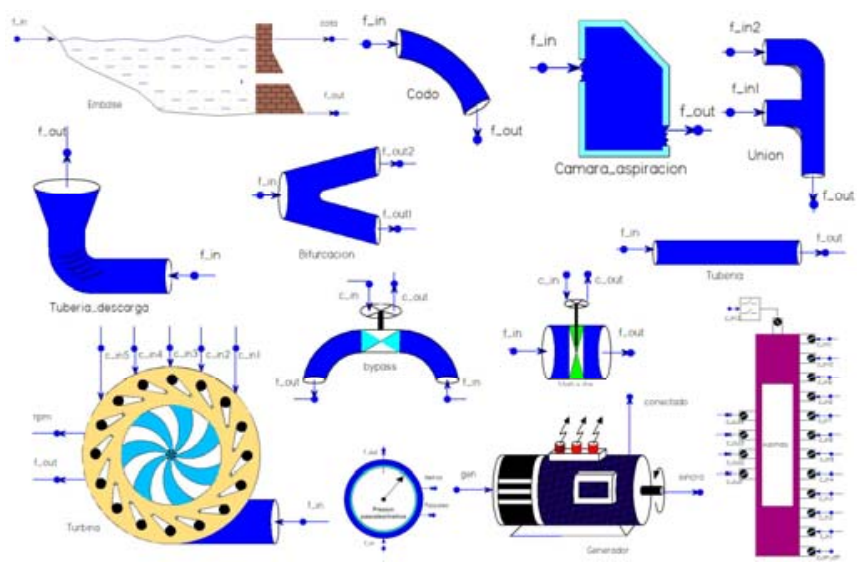

Fig. 3. Graphic symbols of some library components.

Next, some features and advantages of the OOM are explained in more detail and exemplified in some components of the developed library.

\section{A. Encapsulation}

One goal of the OOM is to encapsulate the complexity, separating the external aspects of objects, which can be accessed by other objects, from the internal details, which are hidden from others. A component (or class) is a theoretical description of the structure and behavior of a physical component. Its dynamic equations (if they exist) and discrete events (if any) are included in this description.

As an example, Figure 4 shows the EcosimPro code describing the component "Reservoir". Its internal structure is divided into several sections, some public (accessible) and some private. The parameters and data ports (PORTS and DATA sections) constitute the public, visible part of the component. Local variables, their internal topology, the initialization, the continuous and discrete (DECLS, INIT and CONTINUOUS sections) make up the private part of a component. This private part can be accessed from an experiment, but not from another component. Furthermore, the port definition includes the connection variables and their constraints and behaviors when they are connected to more than one port, in such a way that the connection equations are automatically inserted without the user having to worry about them.

\section{B. Non-causality}

An important consideration of OOM when the dynamic equations of a component are defined is that modelling is NON-CAUSAL. In other words, the causality of the equations is not given, and is resolved during the simulation. Therefore, equations in CONTINUOUS section of the component of Fig. 4 could be written in different ways. For instance, the equation of the reservoir level pressure, in bold, may have adopted any of the following forms without effect on the simulation results: f_out . p=rho*g*h+po; $0=r h *^{*} g^{*} h+p 0-f \_o u t . p$; rho* ${ }^{*} h+p 0=f \_o u t . p ; \quad r h 0^{*} g^{*} h=f \_$out.p-po; ...

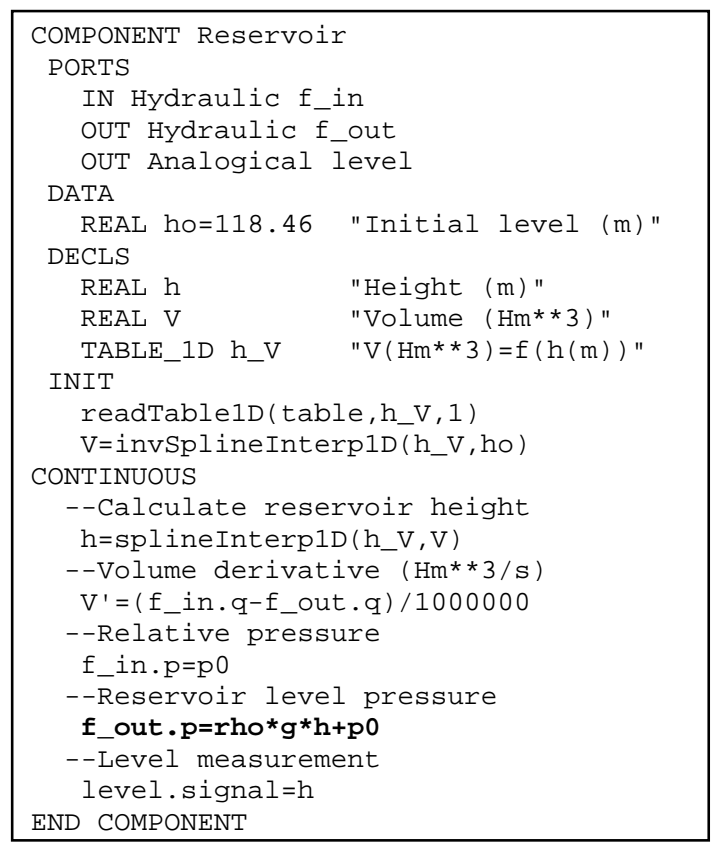

Fig. 4. EcosimPro code of the reservoir component.

In OOM environments, the equations are re-ordered, symbolically modified and checked to assure that there are no problems of singularity or redundant variables, high index, and so on. After compiling the model, the set of equations is formulated as a system of differentialalgebraic equations that is resolved during the simulation, using special resolution methods algorithms based on backward differences, such as DASSL [4], instead of the usual Runge-Kutta.

\section{Inheritance}

Inheritance is a programming concept that provides OOM languages the ability to share interfaces and behaviors, i.e., a way to establish relationships between objects. OOM languages can collect data and common equations in a parent component, which will be inherited by the so-called child components. The child component is complemented with new features (new equations), and can be considered as a refinement or specialization of the general concept defined in its parent component.

In addition, the so-called abstract component is a component that has no real meaning, and is only used to connect a set of variables, equations and discrete events that can be inherited by other components. Abstract components offer the advantage of simplifying child components by reusing checked code. They are inherited by their corresponding child components, but they are not, in general, directly instantiated.

Figure 5 shows the code that constitutes the abstract component code "Conduit" from the developed library. This component defines the common properties of any hydraulic component type, such as input and output ports of water flow and the fact that the sum of input flows equals to the sum of the output flows. Thus, by inheriting 
this abstract component, other components are created with a set of specific characteristics: gates, valves, turbines, pipes, etc.

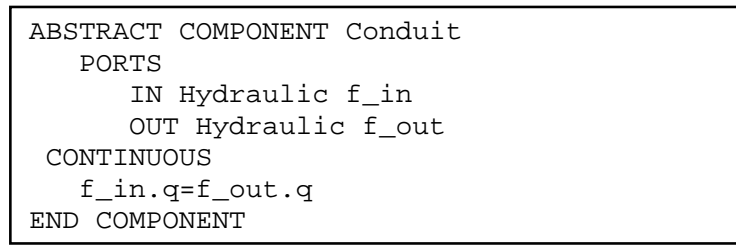

Fig. 5. Code for the abstract component Conduit

\section{Aggregation}

Aggregation is a form of association, in which the object is made up of components. In OOM languages, all the modelled elements are components (or classes). As described in the previous section, a component may inherit from one or several components and can be instantiated multiple times. This feature allows creating components composed from others already developed. In addition, this paradigm is applied iteratively and without limits. The complexity of a final component may be hidden by the aggregation of several components. Figure 6 shows an example of aggregation, with a general scheme of a Kaplan group (top) and its EcosimPro graphic symbol (bottom).

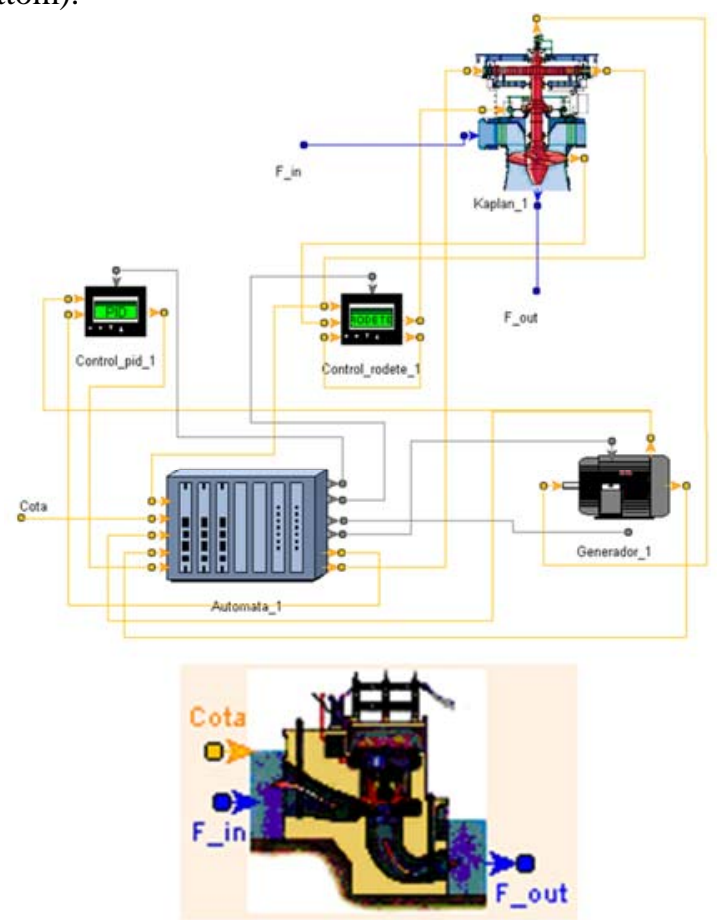

Fig. 6. General scheme and symbol of a Kaplan group

\section{E. Continuous and discrete modelling}

OOM languages must provide the capacity of defining two worlds: the continuous and discrete one. Considering continuous modelling, the user defines the physical model with a set of mathematical equations, which can be algebraic or differential with respect to time. Discrete modelling allows event handling. Events represent things that happen and that the application needs to know, e.g., a pressure value above a defined threshold. When one event occurs, a set of associated actions are executed. In general,
OOM languages specifically developed for continuous systems allow three types of statements: continuous, discrete and sequences. EcosimPro defines different sections for each of the aforementioned types. Sequences are simply a set of statements that are executed sequentially. The discrete section only runs when certain events occur. On the other hand, the continuous section is executed iteratively, each integration step. The most part of the pre-processing operations are applied in this section, such as re-ordering equations, detection of algebraic loops, checking of singularities, etc.

For example, in the developed library for hydropower plants presented in this work, a component that emulates a controller has been designed. The controller regulates the operation of each hydroelectric group independently. The controller is responsible for starting, stopping and connecting the groups to the power grid. The entire program is implemented in the DISCRETE section of the component and runs each sampling period. It is possible to adjust the maximum and minimum load of each group, the reference level, the stop threshold, as well as other parameters.

\section{Practical examples}

In this section, the hydropower plant stations of Navallana and Villafranca are shown, both installed in Córdoba (Spain). They represent practical examples of real small hydroelectric plants, and have been modelled with the developed library.

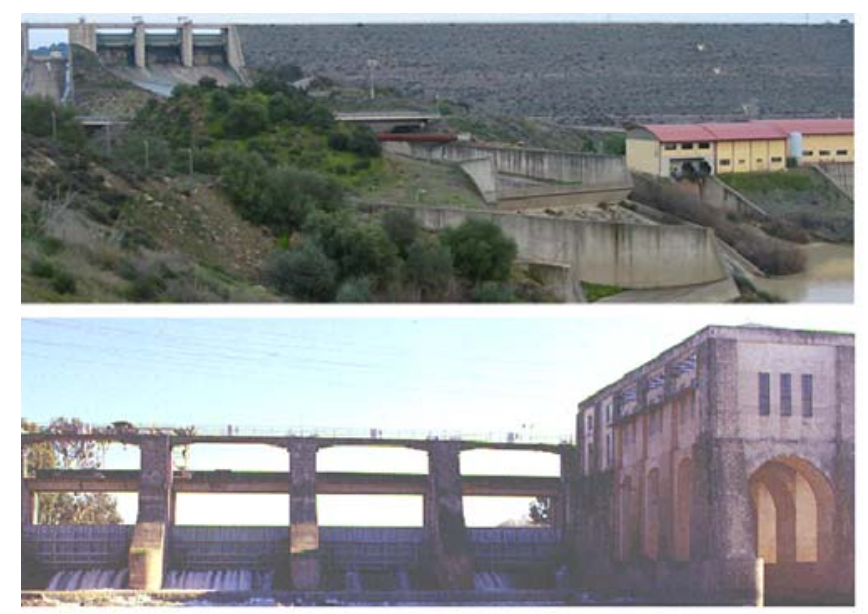

Fig. 7. Hydroelectric plants of Navallana (top) and Villafranca (bottom)

\subsection{San Rafael de Navallana hydropower plant}

San Rafael de Navallana is a hydropower plant installed on the natural bed of Guadalmellato, a reservoir with an approximate volume of $156 \mathrm{hm}^{3}$. This reservoir was specifically built to complete the urban supply and watering. In addition, San Rafael not only stores water from the channel that regulates (Guadalmellato), but can also store water from the Guadalquivir River [5]. The main characteristics of this hydropower plant are summarized as follows:

- Rockfill dam: 57.2 m height, 356 m length. 
- Spillway of $186 \mathrm{~m}$ length.

- Three Tainter gates of $15 \mathrm{~m}$, with a capacity of 1157 $\mathrm{m}^{3} / \mathrm{s}$.

- One hydroelectric unit:

- Nominal power: 4.81 MW

- Specific speed: $428.6 \mathrm{rpm}$

- Francis turbine

- Nominal water flow: $12.5 \mathrm{~m}^{3} / \mathrm{s}$

By instantiation and connection of components from the developed library, the whole scheme of Navallana power station is shown in Fig. 8.

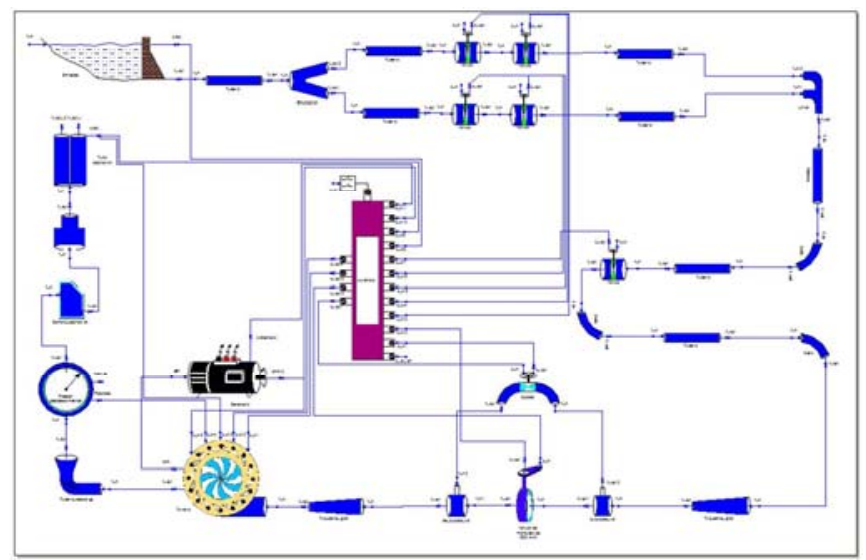

Fig. 8. Model of San Rafael de Navallana hydropower plant.

Once the configuration parameters are set in the different components, the hydropower model was simulated. Simulation results were validated with real data, such as the reservoir level, the generated power and the control valve position. The main initial values of the simulation were as follows:

- Initial reservoir level: 158m.

- Estimated input flow rate to the reservoir: $5.3 \mathrm{~m}^{3} / \mathrm{s}$.

- Estimated friction coefficient: 0.4.

A comparison between simulation results and real data is shown in Table 1. Final result of the reservoir level was $156 \mathrm{~m}$.

Table 1. Comparison of simulation and real data from Navallana station

\begin{tabular}{|c|c|c|}
\hline Variables & Simulation data & Real data \\
\hline $\begin{array}{c}\text { Turbine flow rate } \\
\left(\mathrm{m}^{3} / \mathrm{s}\right)\end{array}$ & 10.109 & 10 \\
\hline Power $(\mathrm{kW})$ & 4051.22 & 4000 \\
\hline Performance $(\%)$ & 0.908 & 0.9 \\
\hline Gate $(\%)$ & 67.5 & 66 \\
\hline
\end{tabular}

Taking into account the simulation results, it is possible to address some changes in the hydropower plant in order to increase its performance. Losses due to friction in friction are important factors to take into account in this type of installations. For example, considering the flow rate shown in Table $1\left(10.109 \mathrm{~m}^{3} / \mathrm{s}\right)$, total load losses in conduits are $436.34 \mathrm{~kW}$. One possible solution to reduce this effect would be to increase the diameter of the pipes. However, in this case, the ideal conditions would not be preserved. Another possibility to mitigate these losses would be to decrease the friction coefficient of the pipes, from 0.4 to
0.1 , corresponding to new welded steel. This new situation could be achieved which a pipe cleaning or a replacement of those which are in very poor condition.

If a new simulation is executed with the new friction coefficient and a practically identical flow rate $(10.096$ $\mathrm{m}^{3} / \mathrm{s}$ ), load losses are reduced to $425.17 \mathrm{~kW}$. Thus, with this modification, an improvement of about $10 \mathrm{~kW}$ in the generated power could be expected.

\subsection{Villafranca hydropower plant}

Villafranca is a flowing type hydropower plant that was built in 1948. Both the dam and the main building are placed together, taking advantage of all the river width in that place. Its main features are as follows [6]:

Hydropower plant with run-of-river scheme built in 1948.

- Reservoir in Guadalquivir River with a capacity of 0.63 $\mathrm{hm}^{3}$ ).

- Nominal power: 2.5 MW

- Specific speed: $187 \mathrm{rpm}$

- 2 Kaplan turbines

- Nominal water flow: $36.5 \mathrm{~m}^{3} / \mathrm{s}$

In a similar way to the previous case, a general model of small hydropower plants with low head run-of-river scheme has been created with the developed library [7]. It consists of the following components: the dam, the spillway, lower water reservoir, four sliding gates, the automation system of the gates, five hydroelectric units that can be configured as Kaplan or Francis. This general model has been configured for the specific case of the Villafranca plant.

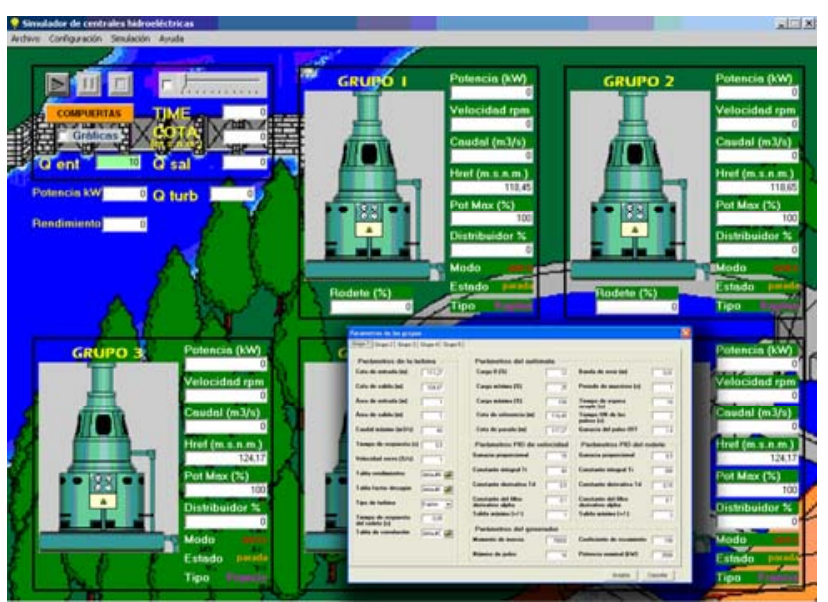

Fig. 9. Main window of the Villafranca hydropower plant simulator

In addition, a graphical tool, a simulator, has been designed for this case. This tool is used to configure the model parameters, to simulate this model and to test its performance in different situations, with the main aim optimizing the plant operation and improving its productivity. The simulator has been designed with Visual Basic 6.0 because experiments generated by EcosimPro can be easily integrated in Visual Basic applications. In order to get a familiar application for operators and to use it as a training tool, the graphical interface has been designed according to SCADA 
standards of real plants [7]. As an example, Figure 9 shows the aspect of the simulator with data about the groups: power output, discharge, efficiency, gate position, state and so on. The parameter configuration window of the groups is also shown.

A simulation was carried out with this model in order to study the plant performance. An input flow of the river about $60 \mathrm{~m}^{3} / \mathrm{s}$ was used, the groups were initially stopped and the initial water level of the dam was set $118.45 \mathrm{~m}$ above sea level. Table 2 shows the stationary results of the main variables used for the validation after one hour. Both units come into operation to control the water level according to the reference of the second unit, $118.65 \mathrm{~m}$ (the reference of the first unit is $118.45 \mathrm{~m}$ ).

Table 2. Results for an input flow of $30 \mathrm{~m}^{3} / \mathrm{s}$

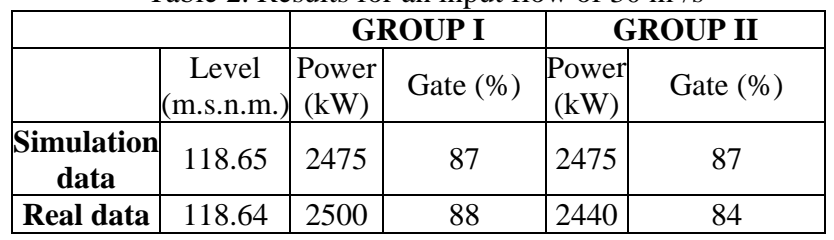

The main differences between the simulation results and real data were found in the transient responses. Despite this fact, the stationary results were very similar.

\section{Conclusions}

In this work, the main advantages of object oriented modelling have been presented. The design and development of complex models, such as hydraulic power plants, where the cost of real experiments is high, has been addressed. As an example, the development of a component library for hydropower plants, based on EcosimPro, was described. This approach takes advantage of OOM and its properties, such as aggregation, inheritance, and modularity.
Two real plants were modelled by using the developed library. Simulations results were compared and validated with real data, showing a good agreement. These results show the benefits of OOM in analyzing and modifying the behavior of hydraulic power plants, with the main idea of improving some aspects like system performance or reduction of starting operations. In addition, the simulation can be used to study the behavior of the plant in unexpected conditions, such as a great flood of the river or different emergency situations.

\section{References}

[1] Dillon, T.S, Change, E. "Solution of power system problems through the use of object-oriented paradigm". International Journal of Electrical Power and Energy Systems. (1994) Vol. 16-3, pp 157-165.

[2] Manzoni A, de Silva A S, Decker I C. "Power System Dynamics Simulation Using Object-Oriented Programming”. IEEE Transactions on Power Systems. (1999) Vol.14-1, pp.249-255.

[3] Agüera, J. "Mecánica de fluidos incompressible y turbomáquinas hidráulicas. $4^{\mathrm{a}}$ edición. Madrid: Editorial Ciencia, (1996), pp 705.

[4] Vázquez, F., Jiménez, J., Garrido, J., Belmonte, A, "Introduction to Modelling and Simulation with EcosimPro”. Madrid: Pearson Educación, (2010), pp. 272.

[5] Estadística de los aprovechamientos hidráulicos existentes en la actualidad en el río Guadalquivir. [Sevilla]: Confederación Hidrográfica del Guadalquivir, (1993).Plan de operación normal de la central hidráulica de Villafranca. [Córdoba]:

[6] Plan de operación normal de la central hidráulica de Villafranca. [Córdoba]: Unidad de Producción Hidráulica Sur de Endesa Generación, (2002), p. 134.

[7] Garrido, J., Zafra, A. \& Vázquez, F., “Object oriented modelling and simulation of hydropower plants with run-ofriver scheme: A new simulation tool”, Simulation Modelling Practice and Theory, (2009) vol. 17, no. 10, pp. 1748-1767. 